Microbiology Series; Microbial Testers: Probing Carcinogenesis. Volume 5. Ed. I. C. Felkner (1981) New York: Marcel Dekker. 264 pp.

Another volume in the current spate of publications on methods for detection of environmental carcinogens by short-term tests, this one purportedly concentrating on microbiological methods and their newer developments and refinements.

Of the 10 chapters in the book however, only 6 deal exclusively with microbiological systems, the remaining 4 being devoted to a discussion of reactions of carcinogens with DNA, inevitably included in such volumes, and the role of intestinal microflora and dietary fats in carcinogenesis. The use of short-term tests other than microbial ones is also commented on briefly in one of the chapters. The book includes an index (subject and author) and a glossary, but the latter contains numerous inaccuracies (e.g. definitions of non-disjunction, HGPRT and epigenetic). To the non-specialist the book may represent a useful overview, but for the specialist in the field there is little information in this volume which is not readily available in other similar books published previously.

M. Fox

Oral Premalignancy. Eds I. C. Mackenzie, E. Dabelsteen \& C. A. Squier (1980) Iowa: Iowa University Press. $353 \mathrm{pp}$. $\$ 32.50$ net.

This book is the result of a symposium on oral premalignancy held a few years ago at the University of Iowa Dental College. For this purpose the editors brought together clinicians, pathologists and researchers. Part one outlines the clinical and histopathological features of oral premalignant lesions; part two covers carcinogenesis in epithelial tissues and the role of Candidal infection; part three is concerned with epithelial models in experimental carcinogenesis (epidermis, cervix, oral mucosa); part four covers structure and cell proliferation in normal and pathological epithelium, the influence of connective tissue, immunological aspects and stereo- logical changes during carcinogenesis. A section on clinical and histological pointers to prognosis completes the volume.

This is a nicely produced book, the chapters being well written with an absence of repetition. With one exception the photographs are of good quality, but there is the occasional spelling error. The lack of an index is offset by each chapter being subdivided into a number of headed sections. Of particular value is the inclusion of a precis of the discussions that followed each group of papers. It is unfortunate that a lengthy delay occurred before these proceedings appeared in print (there are few references for 1978). Predictably this has affected the chapters concerned with normal tissue function.

Minor criticisms include the failure to define "preleukoplakia" and "stem" cells. The latter term is used to indicate different concepts by 3 contributors. It is likely that the reader will disagree wth some of the statements in the discussion sections as well as in individual chapters. For example, in the final sentence of the book, one of the participants advocates the taking of random biopsies of the floor of the mouth (a common site for oral carcinoma) in high-risk patients (elderly males who smoke heavily and drink alcohol) even in the absence of a clinically detectable lesion. This is unacceptable and underlines the need for such a symposium. The editors are to be congratulated for the amount of work they have put into producing this very readable and commendable book.

W. Hume

\section{Neoplastic and Normal Cells in Culture} J. M. Vasiliev \& I. M. Gelfand (1980) Cambridge: Cambridge University Press. 372 pp. $£ 36.00$ net.

In spite of a rather unassuming title this book explores a wide range of properties of tumour cells in vitro related to their escape from normal regulation of growth and motility. Much of the material is now well established tissue-culture lore, but nevertheless it is valuable to have it collected together with a very useful bibliography, and the many still unanswered questions revealed. 
Although the half-tone illustrations are quite frequent and of good quality, there is only one attempt at presenting graphical data. This is unfortunate as it lends an air of qualitative morphological interpretation where, in fact, quantitative analysis has clearly been possible, and is acknowledged in the text.

Most of the relevant literature is well covered, and the over-emphasis on transformed rodent cell lines as models for spontaneous neoplasia perhaps reflects the preoccupation of workers in the field, and the paucity of hard data on short-term cultures from human tumours, rather than any deficency of coverage by the authors.

In summary, the merit of this book lies in its wide coverage of the field, with good references and presented in a clear easily read style. The clarity and brevity of the text could have been improved by more graphic illustration, even at the expense of some of the half-tone plates. A useful book to have, if rather costly at $£ 36$.

\section{R. I. Freshney}

\section{Early Detection of Testicular Cancer.} Eds N. E. Skakkeback, J. G. Berthelsen K. M. GRIGOR \& J. VinfeldT (1981) Copenhagen: Scriptor. 239 pp. 135 Danish Kroner.

This book contains the proceedings and discussion from an International workshop held in Copenhagen in November 1980. The content is wider than the title implies, with sections on the origin and classification of germ-cell tumours, model systems and epidemiological and clinical aspects. These sections are nevertheless useful reviews of these fields.

The incidence of testicular tumours is increasing in many countries, and although even advanced disease may be curable by intensive chemotherapy, early detection is obviously desirable when many patients may be treated by orchidectomy alone. The crucial section is, therefore, that on screening and testicular biopsy of testicular-cancer risk groups. Recent advances have stemmed from Dr Skakkeback's studies of testicular biopsies in infertile men with no signs of testicular tumours. Abnormal germ cells can be recognized in these biopsies, and the consensus opinion is that these usually indicate in situ malignant change. Four risk groups have been identified: the infertile those with atrophic or undescended testis and the contralateral testis of patients with overt testicular tumours. This is therefore an important contribution to the possible early detection of testicular tumours, though there is still disagreement over whether orchidectomy or a watch policy should be adopted in these patients. The final section deals with testicular-tumour markers, both those of established value and those under investigation.

Although all the contributions are of a high standard, some will be of more interest to the laboratory worker than the clinician and vice versa. It seems unlikely that one person would find enough of sufficient interest to buy the book, but it should certainly find its way to the specialist medical library.

G. READ

\section{Developments in Antiviral Therapy. Ed.}

L. H. Collier \& J. OXFORD (1980) London: Academic Press. 291 pp. £18.60 net.

This book records the proceedings of a meeting held in London in November 1979, though not all the papers presented there are in print. Its contents fall into two sections. The first describes drugs acting primarily on the herpes viruses and on RNA respiratory viruses. The second section describes some aspects of interferon research. The 2 sections do not really knit together, but are a useful summary of the results obtained with a number of antiviral drugs and are useful for reference. There is little in the book about future development, though the editors conclude the book with a useful summary and some prospective remarks.

\section{C. Burke}

\section{Chemotherapy of Cancer (2nd Edn).}

S. K. Carter, M. T. Bakowski \& K. Hellmann (1981) Chichester: John Wiley \& Sons. 379 pp. $£ 9.00$ net.

The differences in emphasis between this the second edition and the first edition of this excellent chemotherapy handbook are of great interest. As befits a young subject 4 years older, it has mellowed. Outwardly the editions look identical, but this one has increased in size by 29 pages and has been extensively revised. The first 3 sections (a general introduction, anticancer drugs and 